\title{
Modification of Waste Wool Fiber as Low Cost Adsorbent for The Removal of Methylene Blue from Aqueous Solution
}

\author{
H. H. Abdel Ghafar',2, T. Salem ${ }^{3}$, E.K. Radwan' ${ }^{2}$, A. Atef El-Sayed ${ }^{3}$, M.A. Embaby ${ }^{1,4}$, M. \\ Salama $^{3^{*}}$ \\ ${ }^{1}$ Department of Chemistry, Faculty of Sciences and Arts, Khulais, University of Jeddah, Saudi \\ Arabia. ${ }^{2}$ Department of Water Pollution Research, ${ }^{3}$ Textile Research Division, \\ ${ }^{4}$ Department of Food Toxicology and Contaminants, National Research Centre, El Bohouth St, \\ Dokki, Giza, Egypt 12622.
}

\begin{abstract}
D EMOVAL of methylene blue (MB) from water using adsorbent developed from waste wool fiber has been investigated by batch adsorption experiments in the present work. Wool fiber waste (WF) was collected from a local Spinning and Weaving Company, cleaned and further treated with citric acid to increase its adsorption capacity toward basic dyes. Raw and treated WF were ball milled to produce wool powder (WP) and modified wool powder (MWP), respectively. The carboxyl content was increased steadily as the citric acid solution concentration increased. The introduction of the carboxyl groups also has been proved by streaming potential measurements. The effect of contact time, wool dose and dye solution $\mathrm{pH}$ on the adsorption process were studied too. The adsorption isotherm was examined using Langmuir, Freundlich, and Dubinin-Radushkevich (D-R) models. The adsorption equilibrium was attained within 20 minutes with a maximum removal percentage of 70 and 78 for WP and MWP, respectively. The wool dose affects the adsorption process significantly, especially for MWP which removes a higher percentage of MB (86\%) compared to WP (75\%). Both Freundlich and D-R were well fitting the adsorption equilibrium data with $\mathrm{R}^{2}>0.9$. The values of Freundlich exponent factor (n) and D-R adsorption energy (E) reveal the chemisorption nature of the MB adsorption on both WP and MWP. This work demonstrated that, chemical and physical modifications of the waste wool fiber with citric acid has enhanced the adsorption of MB.
\end{abstract}

Keywords : Dye removal, Wool fiber waste, Isotherm modeling, Adsorption, Wastewater treatment.

\section{Introduction}

Water pollution by dyes is a worldwide problem particularly in textiles, leather, paper, plastics, rubber, cosmetics, pharmaceutical and food industries where large quantities of dye effluents are discharged into the surface water bodies without appropriate treatment [1,2]. Discharge of these dyes presents a major environmental problem for developing countries because of their toxic and carcinogenic effects on living beings, consequently, dyes become a momentous source of water pollution even at trace level [3,4].

Methyleneblue(MB), 3,7-bis(dimethylamino)phenothiazin-5-ium chloride, is one of the widely used cationic azo dyes in the industry[5]. The presence of $\mathrm{MB}$ in the aquatic environment deteriorates the water quality and causes several harmful effects on human and aquatic life.For example, it reduces the photo synthesis process and hampers the ability of aquatic organisms to localize food by interfering the penetration of sunlight and increasing the turbidity in water bodies, correspondingly. Also, it biodegrades slowly thus lasts for a long time in the water bodies and contaminates the food chain. Therefore, the removal of $\mathrm{MB}$ from the aquatic environment is of significant concern [1-3].

Several techniques such as adsorption, photocatalytic degradation, biodegradation, and electro coagulation have been reported in the literature [6-10] for the removal of MB from the aqueous medium, however, the high efficiency, flexibility, ease of operation, simplicity, low cost, and insensitivity to toxic pollutants features make the adsorption technique the most attractive and widely used [1-3, 11]. Nowadays, studies are focused on utilizing agricultural and industrial wastes as adsorbents for dye removaldue to their

*Corresponding author e-mail: , Salama1974@gmail.com, Tel: 01115082873

DOI : 10.21608/ejchem.2017.687.1023

(C)2017 National Information and Documentation Center (NIDOC) 
abundance, low cost, low commercial value, and biodegradability $[1,2,12-15]$.

Waste wool fibers are amply available in Egypt. Utilizing this waste as adsorbent material could cut the cost of adsorption process and provide a solution for waste management [1622]. The presence of functional groups (such as $\mathrm{NH} 2, \mathrm{CONH}_{2}, \mathrm{COOH}$, and $\mathrm{OH}$ ) in the wool [18, 20] makes ita promising sorbent. These groups render wool high binding capacity toward metal ions $[20,23,24]$ and dyes $[25,26]$. In addition, grinding wool into fine powder enhances the wool binding capacity owing to anenormous increase in the specificsurface area, meanwhile, keeping the original features of the wool unchanged $[18,20,27]$. Further enhancement in the wool binding capacity might be attained by chemical modification. It worth noting that the oxidation of wool using a mixture of hydrogen peroxide and Tetraacetylethylenediamine (TAED) improved the wool exchange-ability toward copper and zinc [20].

This study aims at utilizing the abundant waste wool fiber as a low-cost sorbent for dyes removal. The waste wool fiber was treated physically by ball milling and chemically by citric acid to enhance its adsorption capacity. The adsorption performance of the physically and chemically treated waste wool fiber was assessed and compared under different conditions such as aqueous medium $\mathrm{pH}$, sorbent dose, contact time, and initial dye concentration. Finally, the adsorption equilibrium data was modeled using Langmuir, Freundlich, and Dubinin-Radushkevich (D-R) equations.

\section{Materials And Methods}

\section{Chemicals}

Wool fiber waste (WF) was supplied by ElShemy Co for Spinning and Weaving, 10th of Ramadan, Egypt. The characters of these wool fibers are summarized as follows: mean fiber diameter $19.9 \mu \mathrm{m}$, fiber strength $10.2 \mathrm{cN} /$ tex, and alkali solubility $15.7 \%$. The fibers were subjected to scouring process using $1 \mathrm{~g} / \mathrm{L}$ sodium carbonate and $1 \mathrm{~g} / \mathrm{L}$ non-ionic detergent at $60^{\circ} \mathrm{C}$ for 10 min to remove the oily matters added during the carding and combing processes. Wool fibers were then thoroughly rinsed with cold water, squeezed, and finally, air dried at ambient temperature.

Citric acid mono hydrate $\left(\mathrm{C}_{6} \mathrm{H}_{8} \mathrm{O}_{7} \cdot \mathrm{H}_{2} \mathrm{O}\right)$ from
Merck (Germany) was used to modify the WF. Sodium hypophosphite $\left(\mathrm{NaH}_{2} \mathrm{PO}_{2} \cdot \mathrm{H}_{2} \mathrm{O}\right)$ from Ridean de hean (Germany) was used as a catalyst. Analytical grade chemicals were supplied by Merck (Darmstadt, Germany) and used as received.

\section{Wool fiber modification}

The wool modification was carried out by firstly treating the wool fibers with $0.01-0.1$ molar citric acid solution with about $4 \%$ sodium hypophosphate as a catalyst bearing numbers of carboxyl groups at a liquid ratio of $1: 50$, at $75^{\circ} \mathrm{C}$ for $90 \mathrm{~min}$. Wool fibers were then removed from the treatment solution, thoroughly rinsed and allowed to dry at ambient conditions, further drying was carried out by heating in an oven at $105^{\circ} \mathrm{C}$ to attain constant weights. The dry weight of wool samples was determined before and after treatment [28].

\section{Powder preparation}

Wool fibers (WF), as well as citric acid modified wool fibers (MWF), were both milled separately using the ball milling technique (Retsch PM 100, Germany), equipped with zirconium balls, to produce wool powder (WP) and citric acid modified wool powder (MWP). The total milling time was adjusted for 8 hours after each $10 \mathrm{~min}$ takes a rest for $5 \mathrm{~min}$ and start in a reverse direction [20].

\section{Dye solution}

Methylene blue (MB) was used as the adsorbate in this study. $\mathrm{MB}$ is a cationic thiazine dye with the molecular formula of $\mathrm{C}_{16} \mathrm{H}_{18} \mathrm{ClN}_{3} \mathrm{~S}$, molar mass of $373.90 \mathrm{~g} / \mathrm{mol}$ and a maximum absorbance peak in the visible region at a wavelength of $664 \mathrm{~nm}$. The chemical structure of MB is shown in Fig. 1.

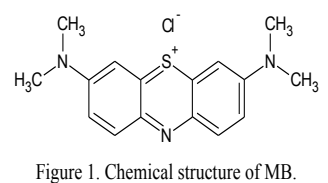

A fresh working solution of MB was prepared for each experiment by dilution of $1 \mathrm{~g} / \mathrm{L}$ stock solution to give the desired initial concentration. Deionized water was used to prepare all solutions. The initial $\mathrm{pH}$ of the working solutions without adjustment was 6.5.

\section{Wool characterization \\ Surface morphology analysis}


The surface morphology of wool fibers and its powders were studied by using HITASHI S-3000 (Hitachi, Japan) microscope, at $15-\mathrm{kV}$ acceleration voltage. The powder surface is coated with a thin layer of gold by Edwards S150B Gold Sputter Coater in order to perform the SEM photos.

\section{Carboxyl content of wool fiber}

Initially pure wool as well as modified wool samples were treated with $0.001 \mathrm{~N} \mathrm{HCl}$ solution for $48 \mathrm{hr}$, then washed with distilled water several times until constant $\mathrm{pH}$ value and samples were then dried in air. Dry wool (5 g) was wetted in $100 \mathrm{~mL}$ solution of $\mathrm{NaOH}(0.3 \mathrm{~N})$ saturated with sodium chloride at $25{ }^{\circ} \mathrm{C}$ for one hour. Wool samples were removed and $10 \mathrm{~mL}$ of the alkaline solution was titrated against standard $\mathrm{HCl}$, and the alkali combining capacity is calculated as follows in Eq. (1) [28]:

$$
\mathrm{C} 00 \mathrm{H} \text { content (meq./100g wool })=\left(\frac{v_{b}-v_{s}}{w_{t}}\right) 100
$$

where: $\quad \mathrm{V}_{\mathrm{b}}$ is the volume of $\mathrm{HCl}$ corresponding to $\mathrm{NaOH}$.

$\mathrm{V}_{\mathrm{s}}$ is the volume of $\mathrm{HCl}$ corresponding to samples.

$\mathrm{W}_{\mathrm{t}}$ is the weight of wool sample.

\section{Streaming potential measurements}

Electrokinetic measurements were carried out to determine the electrokinetic potential $(\zeta)$ of the wool fiber surface as a function of the $\mathrm{pH}$ values of the electrolyte solution using the streaming potential method. The streaming potential was determined using EKA electrokinetic analyzer (Anton Paar GmbH, Graz, Austria) using the cylindrical cell, which was developed for the measurement of fibrous samples. The measuring cell consists of a glass cylinder with inlet and outlet tubes for the electrolyte solution. The fiber sample is mounted between a pair of perforated $\mathrm{Ag} / \mathrm{AgCl}$ disc electrodes. The electrodes are mounted onto movable pistons, which allow a variation of the distance between these electrodes. The $\mathrm{pH}$ values were adjusted with $0.1 \mathrm{~mol} / \mathrm{L}$ $\mathrm{HCl}$ or $0.1 \mathrm{~mol} / \mathrm{L} \mathrm{KOH}$. To prevent a significant change in the ionic strength by adding $\mathrm{HCl}$ and $\mathrm{KOH}$, all measurements were carried out in 10-3 $\mathrm{mol} / \mathrm{L} \mathrm{KCl}$, which is known as an inert electrolyte. The zeta-potential values were calculated from the measured streaming potentials by the use of the Smoluchowski equation [29]. The streaming potential experiments were carried out with the
Electro Kinetic Analyzer (EKA) (Anton Paar $\mathrm{GmbH}$, Graz, Austria).

\section{Adsorption experiments}

Batch adsorption experiments were carried out at $25 \pm 0.1^{\circ} \mathrm{C}$ by adding the wool samples to a series of $100 \mathrm{~mL}$ of $20 \mathrm{mg} / \mathrm{L}$ MB solution (pH 6.5) in a $250 \mathrm{~mL}$ stopper conical flasks. After shaking at $120 \mathrm{rpm}$, samples were withdrawn, filtered, and the $\mathrm{MB}$ concentration in the filtrate was measured using a UV-Vis spectrophotometer (Shimadzu UV-2600) at wavelength $664 \mathrm{~nm}$. The removal percentage (R \%) was calculated by Eq. (2).

$$
\mathbf{R} \%=\left(\frac{c_{o}-c_{e}}{c_{o}}\right) \mathbf{1 0 0}
$$

where $\mathrm{C}_{0}$ and $\mathrm{C}_{\mathrm{e}}$ are the initial and equilibrium concentration of $\mathrm{MB}$ in the solution $(\mathrm{mg} / \mathrm{L})$.

For each series of measurements, duplicate samples, MB standard, and a procedural blank were analyzed. Also, the spectrophotometer was calibrated regularly and calibration was verified before each sample set. The R \% of MB in the procedural blank was insignificant. Mean values of the duplicate samples were used in calculations.

\section{Contact time effect.}

$0.3 \mathrm{~g}$ of the wool samples were added to 100 $\mathrm{mL}$ MB solutions and the flasks were shaken for 100 min. Samples were withdrawn at a pre-set time intervals, and the procedure continued as described above.

\section{Wool amount effect}

Different weights of the wool samples (1 to $10 \mathrm{~g} / \mathrm{L}$ ) were mixed with MB solutions. After shaking for $1 \mathrm{~h}$ the samples were filtered, and $\mathrm{MB}$ concentration in the filtrate was determined.

pH effect.

$0.9 \mathrm{~g}$ of wool samples were shaken for $1 \mathrm{~h}$ with $100 \mathrm{~mL} \mathrm{MB}$ solutions per-adjusted to $\mathrm{pH}$ 3 to 7 then the above-mentioned procedure was continued. The solution $\mathrm{pH}$ was adjusted by $0.1 \mathrm{M}$ $\mathrm{HCl}$ or $0.1 \mathrm{M} \mathrm{NaOH}$ solutions and was measured by a digital $\mathrm{pH}$-meter (GOnDO PL-700PV).

\section{Isotherms study}

In order to optimize the design of adsorption system, it is important to analyze the adsorption equilibrium data. For this purpose, initial $\mathrm{MB}$ concentrations ranging between 10 to $100 \mathrm{mg} / \mathrm{L}$ 
were used to study the adsorption isotherms. The solution $\mathrm{pH}$ was 6.5 and the wool dose was $9 \mathrm{~g} / \mathrm{L}$. The Langmuir, Freundlich, and Dubinin-Radushkevich (D-R) isotherm models were applied to describe the mechanism of MB adsorption on the wool sample sand describe the surface properties and affinity of the wool samples.

\section{The Langmuir model}

The Langmuir model [30] is based on the assumption of the uniform adsorbent surface with adsorption sites of the equal energy of adsorption, availability, and number of molecules that can be carried. Eq. 3 gives the linear form of Langmuir model.

$$
\frac{C_{e}}{Q_{e}}=\frac{1}{Q K_{I}}+\frac{1}{Q} C_{e}
$$

where $\mathrm{Q}(\mathrm{mg} / \mathrm{g})$ is the Langmuir maximum adsorption capacity, $\mathrm{K}_{\mathrm{L}}(\mathrm{L} / \mathrm{mg})$ is the Langmuir constant related to the equilibrium of adsorption, and $\mathrm{q}_{\mathrm{e}}(\mathrm{mg} / \mathrm{g})$ is the equilibrium dye concentration per gram of wool which was calculated by Eq. 4;

$$
\boldsymbol{q}_{e}=\frac{\left(C_{0}-C_{e}\right) \mathbf{v}}{\mathbf{W}}
$$

where $\mathrm{W}$ is the weight of wool $(\mathrm{g})$ and $\mathrm{V}$ is the volume of MB solution (L).

Conversely, Freundlich model [31] assumes a heterogeneous adsorbent surface with adsorption sites of different energy of adsorption, and availability. The linear form of Freundlich model is shown in Eq. 5.

$$
\log q_{e}=\log K_{f}+\frac{1}{n} \log C_{e}
$$

where $\mathrm{K}_{\mathrm{f}}$ and $\mathrm{n}$ are the Freundlich constants related to adsorption capacity and adsorption intensity, respectively.

\section{The Dubinin-Radushkevich model}

The Dubinin-Radushkevich model [32] predicts the nature of the adsorption process either physical or chemical. The linear form is given in Eq. 6;

$$
\ln q_{e}=\ln q_{m}-\beta \varepsilon^{2}
$$

where $q_{m}$ is D-R's monolayer capacity $(\mathrm{mg} / \mathrm{g}), \beta$ is constant related to adsorption energy and $\varepsilon$ is Polanyi potential, which can be calculated by Eq. 7;

$$
\approx=R T \ln \left(1+\frac{1}{C_{e}}\right)
$$

where $\mathrm{R}$ is the ideal gas constant $(8.314 \mathrm{~J} / \mathrm{mol} \mathrm{K})$, and $\mathrm{T}$ is the absolute temperature $(\mathrm{K})$. The value of $\beta$ derived from Eq. 5 was used to calculate the adsorption energy (E) according to Eq. 8;

$$
E=\frac{1}{\sqrt{-2 \beta}}
$$

\section{Results and Discussion}

\section{Characterization}

Surface morphology

Figure 2 shows the SEM of wool fiber, modified wool fiber (0.07 molar citric acid solution), wool powder and modified wool powder. Figure 2 (A and B) shows the normal structure of wool fibers as well as it clarifies the existence of the scale structure of wool fibers after citric acid modification step. Figure 2 (C and D), elucidates that both wool powder and modified wool show heterogeneous particle size distribution. It is worth noting that, regarding our previous research [20] the milling process of wool fibers at similar milling conditions leads to an increase in the specific surface area from $(0.97 \mathrm{~m} 2 / \mathrm{g})$ to $(259 \mathrm{~m} 2 / \mathrm{g})$ for WF and WP, respectively.

\section{Alkali Combining Capacity}

The effect of citric acid solution concentration on the alkali combining capacity (carboxyl content) of the wool fiber was investigated. Figure 3 illustrates the relation between the carboxyl content (meq. /100 g wool) of unmodified and modified wool versus citric acid solution concentration. It was observed that the carboxyl content was increased steadily as the citric acid solution concentration increased, till reaching a maximum value of 670.9 meq. $/ 100 \mathrm{~g}$ wool at citric acid conc. of 0.07 molar. After which no appreciable increase was observed and so the wool sample of carboxyl content of 670.9 meq. /100 g wool was milled and used for dye removal study.Proposed reactions between wool fiber and citric acid were illustrated in Eq.9 and 10;

$$
W-\mathrm{OH}+\mathrm{HOOC}-\mathrm{R} \rightarrow \mathrm{W}-\mathrm{OOC}-\mathrm{R}+\mathrm{H}_{2} \mathrm{O}
$$




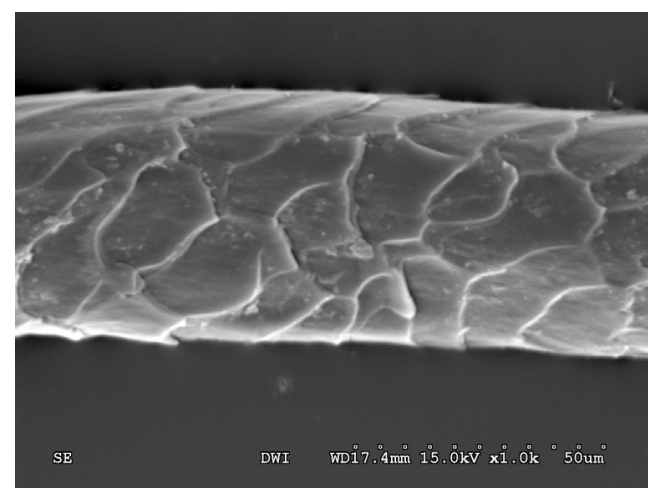

A: Wool Fiber

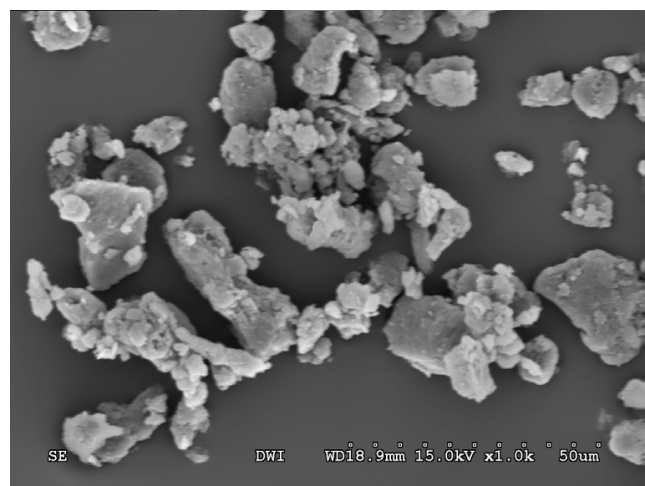

C: Wool powder (WP)

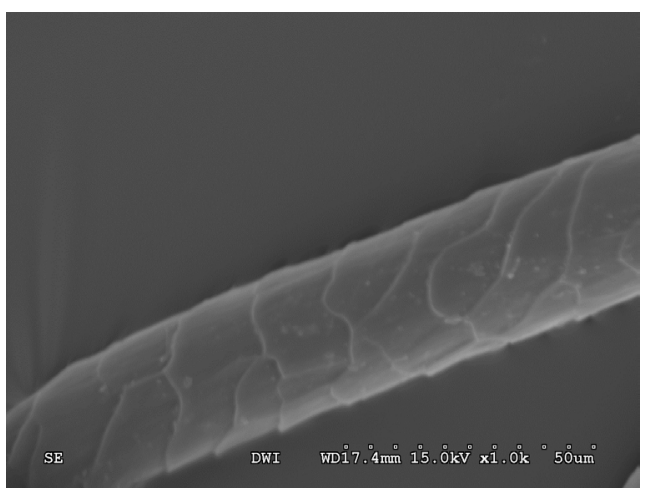

B: Modified wool fiber

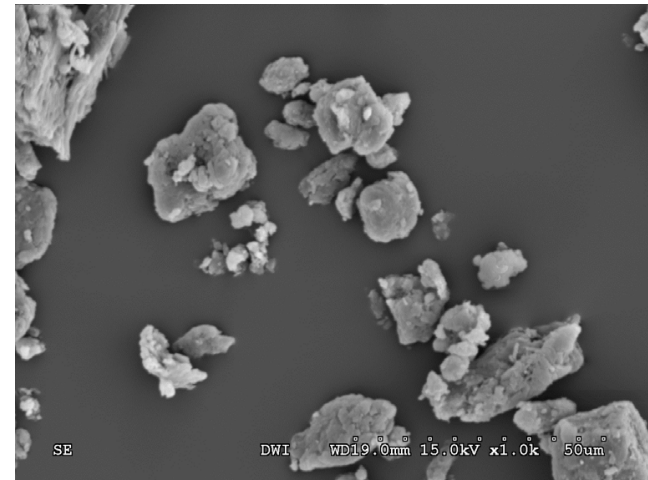

D: Modified Wool powder (MWP)

Fig. 2. SEM of wool fiber, modified wool fiber, wool powder and modified wool powder.

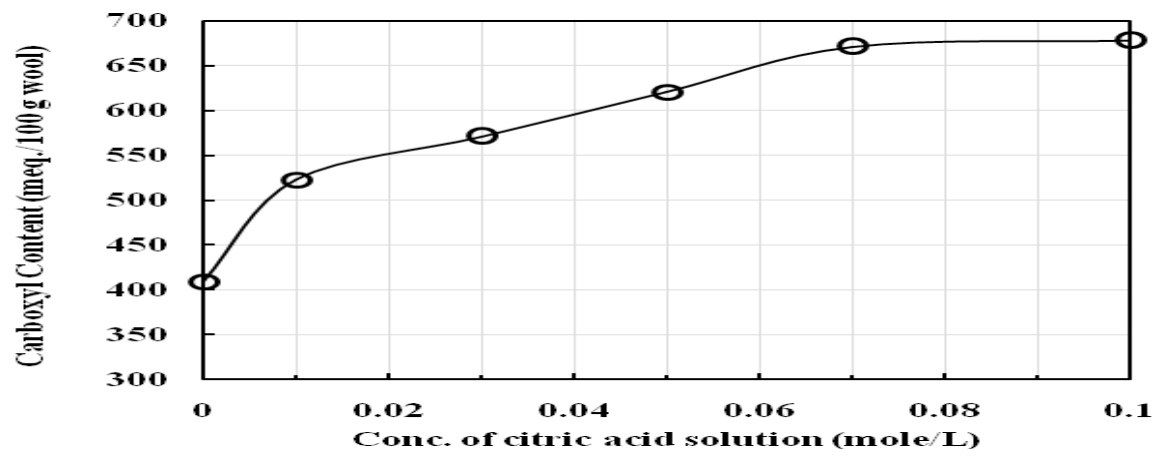

Fig. 3. The relation between conc. of the citric acid solution and the carboxyl content of wool fiber.

$W-\mathrm{NH}_{2}+\mathrm{HOOC}-\mathrm{R} \rightarrow \mathrm{W}-\mathrm{NHOC}-\mathrm{R}+\mathrm{H}_{2} \mathrm{O}(10)$

where $\mathrm{W}-\mathrm{OH}$ and $\mathrm{W}-\mathrm{NH}_{2}$ are wool fiber, HOOC-R is citric acid

Streaming potential measurements

The introduction of the Brønsted-acidic carboxyl groups can be additionally proved by streaming potential measurements that are very sensitive to analyze charge formation processes on solid surfaces. Figure 4 shows the determined zeta-potential values $(\zeta)$ for the unmodified and citric acid modified wool fibers as a function 
of the $\mathrm{pH}$ values of an aqueous $\mathrm{KCl}$ with a concentration of $10-3 \mathrm{~mol} / \mathrm{L}$ solution. At $\mathrm{pH}<$ 5.2 , the zeta-potential of the unmodified wool fiber is positive because of the adsorption of $\mathrm{H}_{3} \mathrm{O}^{+}$ions from the electrolyte solution onto the fiber surface. With increasing the $\mathrm{pH}$ value, zetapotential decreases. At $\mathrm{pH}=5.2$ there is neither an excess of negative nor positive charges in the shear plane where the numbers of protonated amino groups and deprotonated carboxylic acid groups approximately equal [33]. Therefore, the corresponding zeta-potential is zero. The $\mathrm{pH}$ value where zeta-potential equals to zero is called the isoelectric point $(\mathrm{IEP}=\mathrm{pH} \mid \zeta=0)$. At $\mathrm{pH}>\mathrm{IEP}$, (-ev) zeta-potential values are detected, which could be attributed to the preferential adsorption of hydroxide ions from the electrolyte solution.

Influence of treatment wool fibers with citric acid was also investigated by use of streaming potential measurements. Figure 4 shows that in comparison with the unmodified wool fiber surface, IEP shifted to lower $\mathrm{pH}$ values. The IEP shift is mainly obtained by the existence of negatively charged carboxylate groups $(\mathrm{O}=\mathrm{C}-\mathrm{O}-)$, which are taking part to the overall surface charge [34].

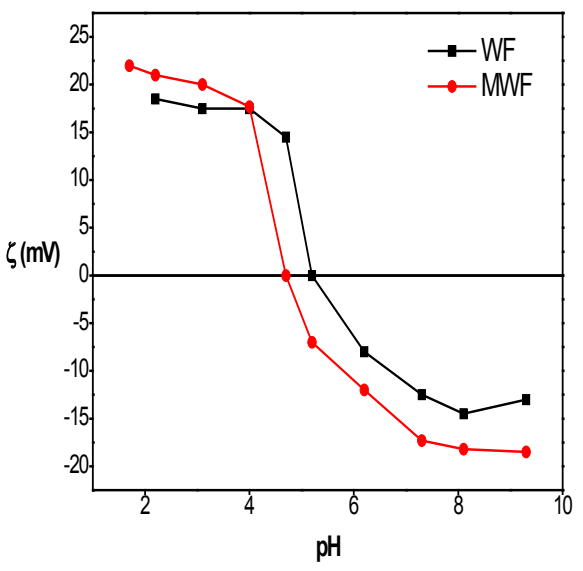

Fig. 4. Zeta potential for unmodified wool fabric (WF) and modified wool fabric (MWF) with citric acid as a function of $\mathrm{pH}$ (in $1 \mathrm{mMKCl}$ ).

\section{Optimum conditions}

Effect of contact time

Figure 5 displays the percentage of MB removed by the studied wool samples against contact time. It is obvious that the dye removal is a fast process that occurs in the beginning of contact time, up to 15 minutes. But prolonging the contact time over 20 minutes causes slight dye desorption. In addition, it is observed that the wool sample MWP removes $78 \%$ of MB in the first 15 minutes which is higher than the percentage removed by WP $(70 \%)$ at the same period. This observation might be due to the higher carboxyl content of MWP which leads to higher MB removal through electrostatic attraction between the positively charged $\mathrm{MB}$ (solution $\mathrm{pH}>\mathrm{pKa}$, $\mathrm{MB}$ ) and the negatively charged surface of MWP (solution $\mathrm{pH}>\mathrm{pH}_{\mathrm{pzc}}$ ).

\section{Effect of dose}

Figure 6 shows the removal of MB by different doses of the studied wool samples. It is seen from the figure that the removal percentage increases with increasing the dose of wool samples. This might be owing to the increase ofadsorption sites. A significant increase occurs at wool doses from 1 to $5 \mathrm{~g} / \mathrm{L}$ and from 1 to $3 \mathrm{~g} / \mathrm{L}$ for MWP and WP, respectively. Further increase in the wool dose to $7 \mathrm{~g} / \mathrm{L}$ resulted in slight increase in the MB removal percentage, which remains constant thereafter. This might be a consequence of the formation of wool aggregates at high doses. Noteworthy that the effect of dose was more obvious for MWP which removes ahigher percentage of MB (86\%) compared to WP (75\%).

\section{Effect of $p H$}

The aqueous medium $\mathrm{pH}$ plays an important role in the uptake of the adsorbate due to the variation of the chemical characteristics of both adsorbate and adsorbent with $\mathrm{pH}$. The effect of solution $\mathrm{pH}$ on the adsorption of $\mathrm{MB}$ on wool samples is shown in Fig. 7. It can be seen that the removal of $\mathrm{MB}$ increased with increasing the initial solution $\mathrm{pH}$ to 5 then remain almost constant for both WP and MWP. However, when the $\mathrm{pH}$ increased to 6.5 an insignificant effect $(\leq 5 \%)$ on the removal percentage can be observed, decrease for WP and increase for MWP. The low removal percentage observed at $\mathrm{pH}$ less than 5 might be due to the existence of $\mathrm{H}_{3} \mathrm{O}^{+}$ions that competes the $\mathrm{MB}$ cationic groups for the adsorption sites [35]. When the $\mathrm{pH}$ of the solution increases, the surface charge density decreases, therefore, the electrostatic repulsion between the cationic groups in the dye molecule and the wool surface decreases and the removal percentage increases.

\section{Equilibrium studies and isotherm modeling Langmuir model}




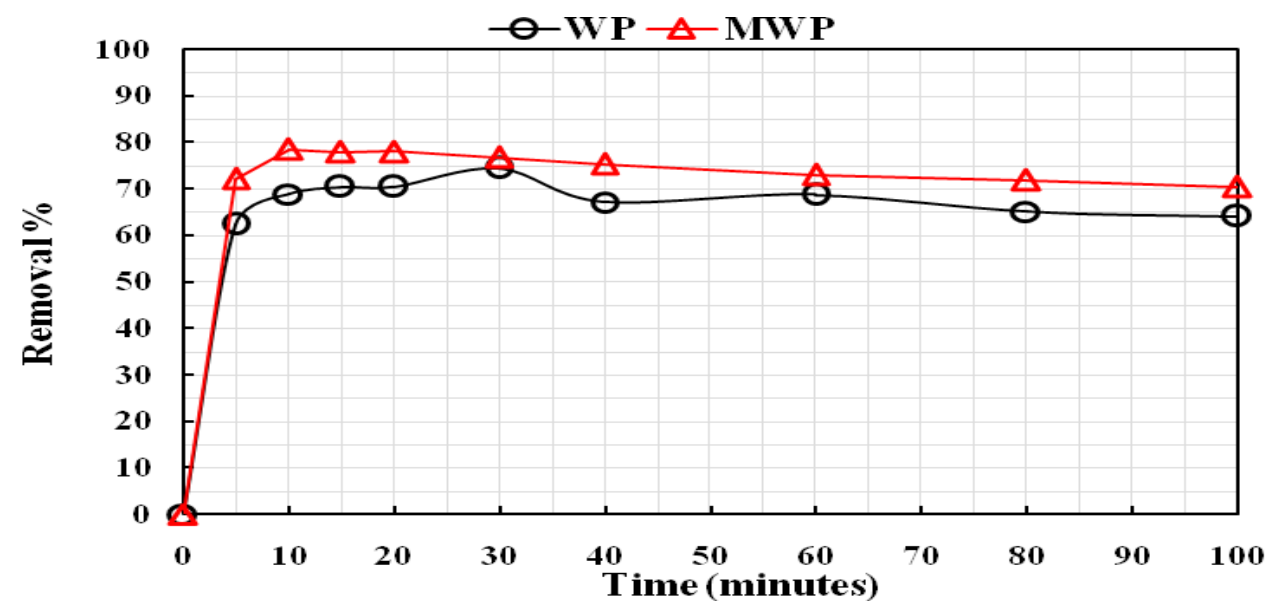

Fig. 5. MB removal percentage as a function of contact time. $C_{0}=20 \mathrm{mg} / \mathrm{L}$; wool dose $=3 \mathrm{~g} / \mathrm{L} ; \mathrm{pH}=6.5$.

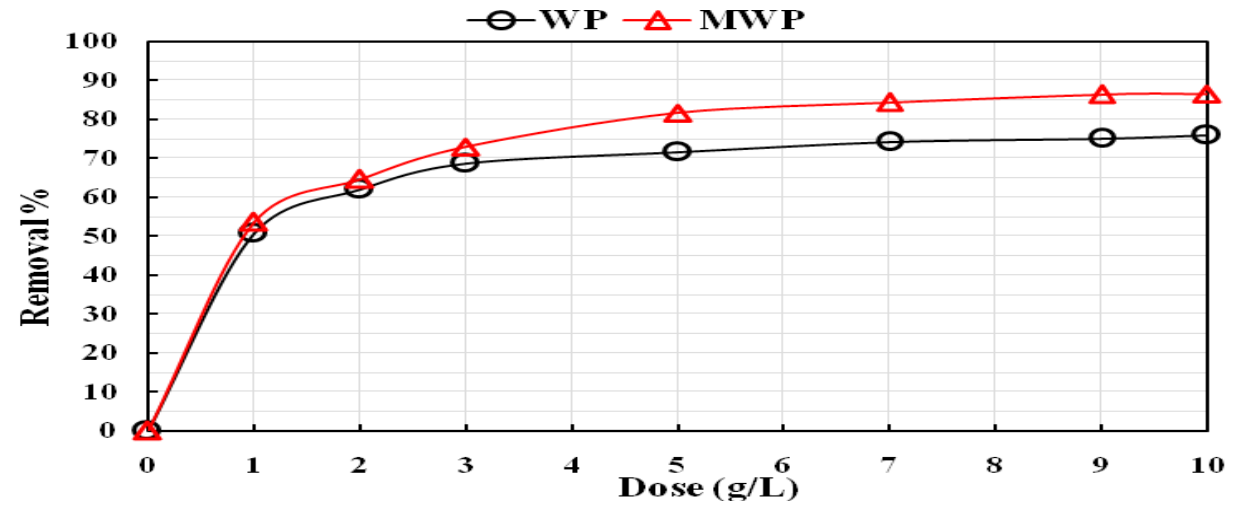

Fig. 6. $\mathrm{MB}$ removal percentage as a function of wool dose. $\mathrm{C}_{0}=20 \mathrm{mg} / \mathrm{L}$; contact time $=1 \mathrm{hr} ; \mathrm{pH}=6.5$.

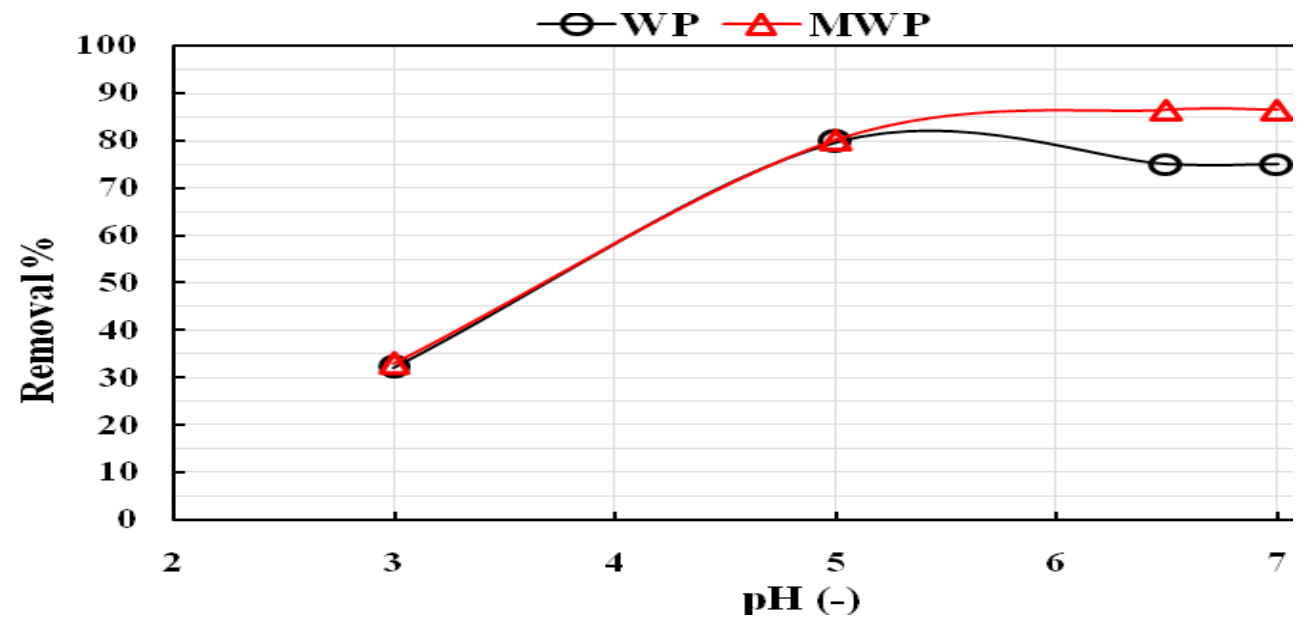

Fig. 7. $\mathrm{MB}$ removal percentage as a function of initial solution $\mathrm{pH} . \mathrm{C}_{0}=20 \mathrm{mg} / \mathrm{L}$; contact time $=1 \mathrm{hr}$; wool dose $=7 \mathrm{~g} / \mathrm{L}$. 
Figure 8 illustrates the plot of $\mathrm{C}_{\mathrm{e}} / \mathrm{q}_{\mathrm{e}}$ versus $\mathrm{Ce}$ for the obtained experimental data of the studied samples. The values of the fitting parameters and correlation coefficient are listed in Table 1. The low $R_{2}$ values show that the Langmuir model did not fit the adsorption data. Accordingly, it could not be dependably employed to explain the isotherm data.
Freundlich model

A straight line with $\mathrm{R}_{2}$ values $>0.9$ (Table 1) was obtained when $\log \mathrm{q}_{\mathrm{e}}$ was plotted versus $\log \mathrm{C}_{\mathrm{e}}$ (Fig. 9) suggesting the applicability of the Freundlich model. Consequently, the model parameters, $\mathrm{K}_{\mathrm{f}}$ and $\mathrm{n}$, were calculated to extract further interpretation of the isotherm. Table 2 shows that MWP has higher $\mathrm{K}_{\mathrm{f}}$ value than WP which mean that, for

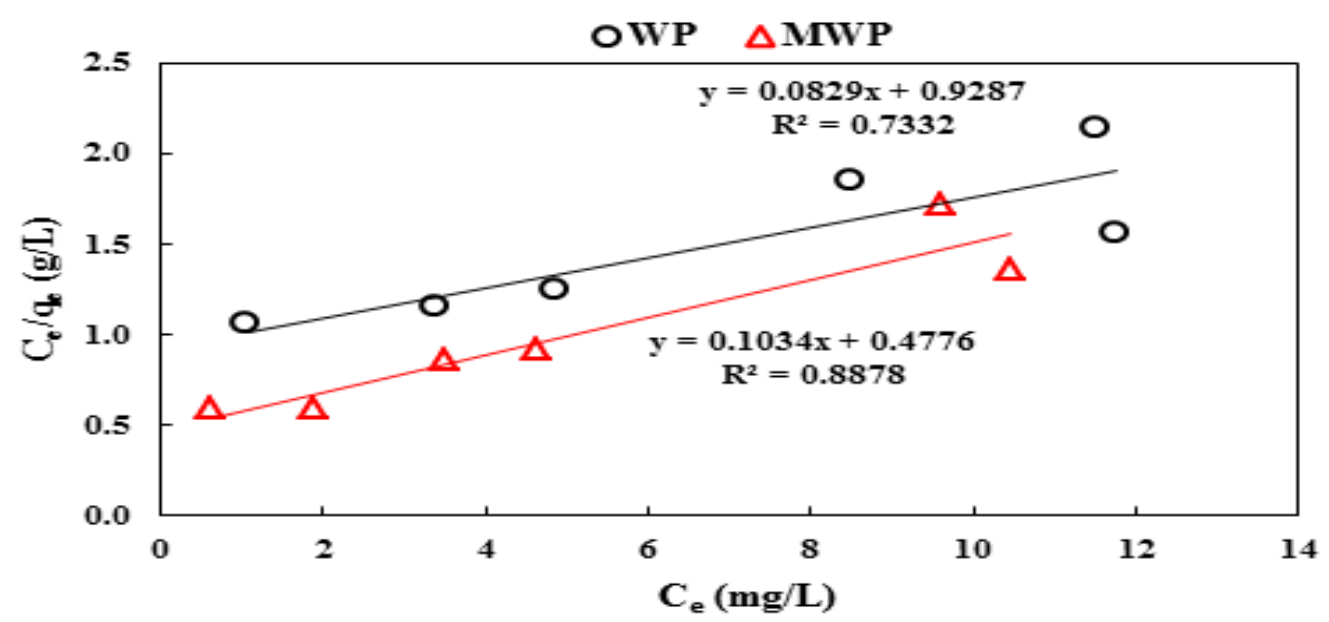

Fig. 8. Langmuir plot for the adsorption of MB on the wool samples. pH 6.5; wool dose $7 \mathrm{~g} / \mathrm{L}$; contact time $1 \mathrm{~h}$.

TABLE 1. Calculated isotherms parameters.

\begin{tabular}{cccc}
\hline Model & Parameter & WP & MWP \\
\hline \multirow{3}{*}{ Langmuir } & $\mathrm{R}^{2}$ & 0.73 & 0.89 \\
& $\mathrm{Q}$ & 12.06 & 9.67 \\
& $\mathrm{~K}_{\mathrm{L}}$ & 0.09 & 0.22 \\
\hline \multirow{2}{*}{ Freundlich } & $\mathrm{R}^{2}$ & 0.96 & 0.94 \\
& $\mathrm{~K}_{\mathrm{f}}$ & 1.06 & 1.70 \\
& $\mathrm{n}$ & 1.35 & 1.59 \\
\hline Dubinin- & $\mathrm{R}^{2}$ & 0.96 & 0.95 \\
Radushkevich & $E(\mathrm{~kJ} / \mathrm{mol})$ & 9.69 & 10.61 \\
\hline
\end{tabular}

a unit equilibrium concentration, WP adsorbs higher quantity of MB than WP. Also, it can be seen that both samples have $\mathrm{n}$ values higher than one indicating the favorable adsorption of $\mathrm{MB}$ on both samples [36]. In addition, it has to be reported that $\mathrm{n}$ values higher than one are indicative of chemisorption [37].

\section{Dubinin-Radushkevich model}

The linear plots of the Dubinin-Radushkevich model based on Eq. (5) are presented in Fig. 10 and the calculated isotherm parameters are listed in Table 1. At the adsorption energy (E) ranges from 1 to $8 \mathrm{~kJ} / \mathrm{mol}$ the adsorption is seemed to be a physical adsorption, while when E ranges from 8 to $16 \mathrm{~kJ} / \mathrm{mol}$ the adsorption is chemical adsorption [38]. Table 1 shows that the E-values for both WP and MWP are in the range of $8-16 \mathrm{~kJ} / \mathrm{mol}$, indicating that the type of adsorption is basically chemical. Therefore, both D-R adsorption energy (E) and Freundlich exponent factor (n) suggest that the MB is chemisorbed on the studied wool samples.

\section{Conclusions}

It was verified that waste wool powder and citric acid modified waste wool power might be a potent sorbent material to be applied in the removal of $\mathrm{MB}$ from the aqueous medium.The milling process of wool fibersat similar milling conditions leads to an increase in the specific surface area from $\left(0.97 \mathrm{~m}^{2} / \mathrm{g}\right)$ to $\left(259 \mathrm{~m}^{2} / \mathrm{g}\right)$ for WF and WP, respectively. The carboxyl content was increased steadily as the citric acid solution concentration increased, to reach a maximum value of 670.9 meq. / $100 \mathrm{~g}$ wool. The introduction of the carboxyl groups has been proved by streaming potential measurements. In comparison with the unmodified wool fiber surface, lower IEP shift is mainly obtained by the existence of negatively charged carboxylate groups $(\mathrm{O}=\mathrm{C}-\mathrm{O}-)$. Several factors were assessed, including contact 
time, wool dose, the solution $\mathrm{pH}$, and initial MB concentration. The optimum conditions were reached at a contact time of $1 \mathrm{hr}$, wool dose of $7 \mathrm{~g} / \mathrm{L}$ and at $\mathrm{pH}$ 6.5. Adsorption equilibrium data were best fitted by the Freundlich isotherm model, suggesting the formation of multilayer of
MB at the wool surface. Moreover, the interaction between the wool and MB molecules was probably a chemisorption process, as advised by the D-R model.

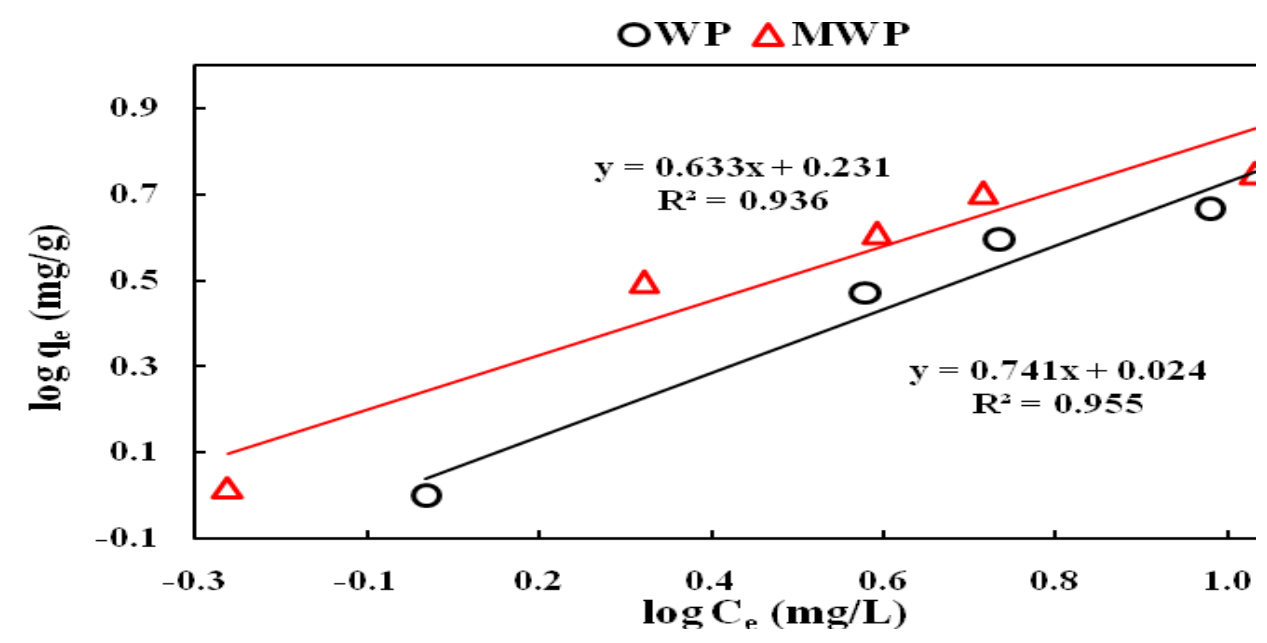

Fig. 9. Freundlich plot for the adsorption of MB on the wool samples. pH 6.5; wool dose $7 \mathrm{~g} / \mathrm{L}$; contact time $1 \mathrm{hr}$.

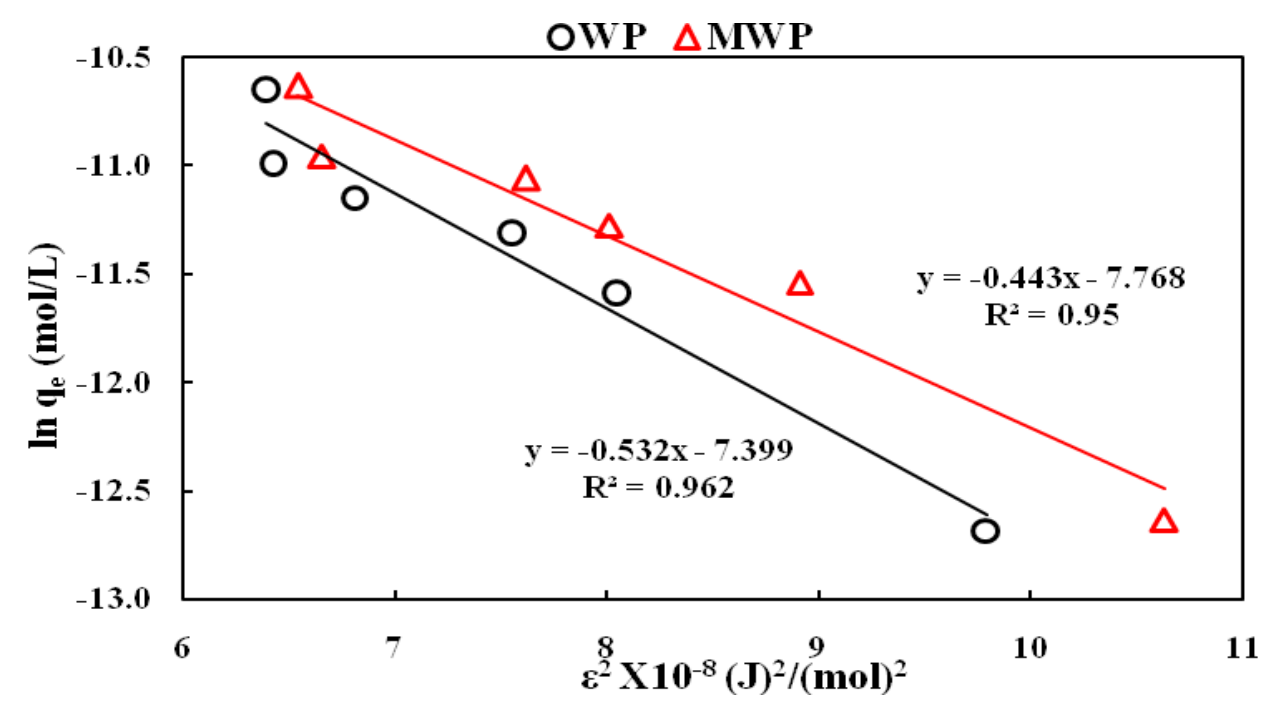

Fig. 10. Dubinin-Radushkevich plot for the adsorption of MB on the wool samples. pH 6.5; wool dose 7 $\mathrm{g} / \mathrm{L}$; contact time $1 \mathrm{hr}$. 


\section{References}

1. Khanday, W.A., Marrakchi, F., Asif, M., Hameed B.H., Mesoporous zeolite-activated carbon composite from oil palm ash as an effective adsorbent for methylene blue, Journal of the Taiwan Institute of Chemical Engineers, 70 , 3241 (2017).

2. Singh H., Chauhan G., Jain A.K., Sharma, S. Adsorptive potential of agricultural wastes for removal of dyes from aqueous solutions, Journal of Environmental Chemical Engineering, 5, 122135 (2017).

3. Spagnoli,,A.A., Giannakoudakis, D.A., Bashkova, $\mathrm{S}$. Adsorption of methylene blue on cashew nut Shell based carbons activated with zinc chloride: The role of surface and structural parameters, Journal of Molecular Liquids, (2017).

4. Ay, Ç.Ö., Özcan, A.S., Erdoğan, Y., Özcan, A. Characterization of Punica granatum L. peels and quantitatively determination of its biosorption behavior towards lead (II) ions and Acid Blue 40, Colloids and Surfaces B: Biointerfaces, 100, 197204 (2012).

5. M. Rafatullah, O. Sulaiman, R. Hashim, A. Ahmad, Adsorption of methylene blue on lowcost adsorbents: a review, Journal of hazardous materials, 177, 70-80 (2010).

6. Liu Y., Jin W., Zhao Y., Zhang, G., Zhang, W. Enhanced catalytic degradation of methylene blue by $\alpha-\mathrm{Fe}_{2} \mathrm{O}_{3}$ /graphene oxide via heterogeneous photo-Fenton reactions, Applied Catalysis $B$ : Environmental, 206, 642-652 (2017).

7. Sarioglu, O.F., Keskin N.O.S., Celebioglu, A. Tekinay T., Uyar, T. Bacteria encapsulated electrospun nanofibrous webs for remediation of methylene blue dye in water, Colloids and Surfaces B: Biointerfaces, 152 , 245-251 (2017).

8. Rodríguez-Cabo,B.,Rodríguez-Palmeiro,I., Corchero R., Rodil, R., Rodil, E., Arce, A.C, Soto, A. Photocatalytic degradation of methyl orange, methylene blue and rhodamine $\mathrm{B}$ with $\mathrm{AgCl}$ nanocatalyst synthesised from its bulk material in the ionic liquid $\left[\mathrm{P}_{66_{614}}\right] \mathrm{Cl}$, Water Science and Technology, 75 , 128-140 (2017).

9. Al-Amrani, W.A., Lim, P.-E., Seng,C.-E., Wan
Ngah, W.S. Factors affecting bio-decolorization of azo dyes and COD removal in anoxic-aerobic REACT operated sequencing batch reactor, Journal of the Taiwan Institute of Chemical Engineers, 45, 609-616 (2014).

10. de Carvalho, H.P., Huang, J., Zhao, M., Liu, G. Dong,L., Liu, X Improvement of Methylene Blue removal by electrocoagulation/banana peel adsorption coupling in a batch system, Alexandria Engineering Journal, 54, 777-786 (2015).

11. Hassan, A.F. Elhadidy, H. Production of activated carbons from waste carpets and its application in methylene blue adsorption: Kinetic and thermodynamic studies, Journal of Environmental Chemical Engineering, (2017).

12. Vaz,M.G., Pereira,A.G.B., Fajardo,A.R. Azevedo, A.C.N., Rodrigues, F.H.A. Methylene blue adsorption on chitosan-g-poly(acrylic acid)/rice husk ash superabsorbent composite: Kinetics, equilibrium, and thermodynamics, Water, Air, \& Soil Pollution, 228, 14 (2016).

13. Lessa,E.F. , Gularte, M.S., Garcia, E.S. ,. Fajardo, A.R., Orange waste: A valuable carbohydrate source for the development of beads with enhanced adsorption properties for cationic dyes, Carbohydrate Polymers, 157 , 660-668 (2017).

14. Zhang, L.Y., Zhang,W., Zhou, Z., Li, C.M. $\gamma-\mathrm{Fe}_{2} \mathrm{O}_{3}$ nanocrystals - anchored macro / meso - porous graphene as a highly efficient adsorbent toward removal of methylene blue, Journal of colloid and interface science, 476, 200-205 (2016).

15. Djelloul,C., Hamdaoui,O. Dynamic adsorption of methylene blue by melon peel in fixed-bed columns, Desalination and Water Treatment, 56, 2966-2975 (2015).

16. Salama,M., Hassabo,A.,. El-Sayed,A.A., Salem, T., Popescu,C. Reinforcement of polypropylene composites based on recycled wool or cotton powders, Journal of Natural Fibers, 1-14 (2017).

17. El-Sayed,A.A. Salama, M. El-Rafie, M. Emam, H.E. Modified rice straw as a template in syntheses of nano $\mathrm{TiO}_{2}$ loaded on wool fibers for wastewater treatment, journal of Natural Fibers, 1-13 (2016).

18. Hassabo,A.G.,Salama,M.,Mohamed, A.L.,.Popescu, C. Ultrafine wool and cotton powder and their

Egypt.J.Chem. Vol. 60, No.3 (2017) 
characteristics, Journal of Natural Fibers, 12, 141153 (2015)

19. El-Kheir,A.A., Popescu,C. Mowafi,S., Salama, M., El-Sayed,H. Physico-chemical properties of keratin-polyvinyl alcohol composite, Fibers and Polymers, 16, 537-542 (2015).

20. Atef El-Sayed,A. Salama, M. Kantouch,A.A.M. Wool micro powder as a metal ion exchanger for the removal of copper and zinc, Desalination and Water Treatment, 56, 1010-1019 (2015)

21. Hassabo,A.G., Salama, M., Popescu,C. Characterizations of PVA composites based on recycled ultrafine cotton and wool powders, Research and Reviews in BioSciences, 10, 147-158 (2015).

22. Salama, M., Mowafi,S., El-Kheir,A.A., El-Gabry, L., El-Sayed, H. Preparation and characterization of polyacrylic/keratin composites: Physicomechanical and biological properties, Life Science Journal, 11 (2014).

23. Richardson,M.J., Johnston, J.H. Sorption and binding of nanocrystalline gold by Merino wool fibres - an XPS study, Journal Of Colloid And Interface Science, 310, 425-430 (2007).

24. Sheffield, A. Doyle,M.J. Uptake of copper (II) by wool, Textile Research Journal, 75, 203-207 (2005).

25. Khan, A.R.,Tahir,H., Waqar,S., Adsorption of methylene blue and malachite green from aqueous solution on the surface of wool carbonizing waste, Journal of Saudi Chemical Society, 9, 427-436 (2005).

26. Saleem,M. Pirzada, T. Qadeer,R. Sorption of some azo-dyes on wool fiber from aqueous solutions, Colloids and Surfaces A : Physicochemical and Engineering Aspects, 260, 183-188 (2005).

27. Xu, W. Wang, X. Li, W. Peng, X. Liu,X. Wang, X.G. Characterization of superfine wool powder/ poly (propylene) blend film, Macromolecular materials and engineering, 292, 674-680 (2007).

28. Bendak,A.,Raslan,W.,Salama,M.Treatment of wool with metal salts and their effects on its properties, Journal of Natural Fibers, 5, 251-269 (2008).
29. Jacobasch,H., Simon,F., Werner, C. Bellmann,C. Determination of the zeta potential from streaming potential and streaming current measurements, Technisches Messen, 63, 447-452 (1996).

30. Langmuir,I., The adsorption of gases on plane surfaces of glass, mica and platinum, Journal of the American Chemical society, 40, 1361-1403 (1918).

31. Freundlich, H.M.F. Over the adsorption in solution, Journal of Physical Chemistry, 57, 385-470 (1906).

32. Dubinin,M.M.Radushkevich, L.V. The equation of the characteristic curve of the activated charcoal, Proc. Acad. Sci. USSR Phys. Chem. Sect. , 55, 331337 (1947).

33. Rippon, J.A. The structure of wool, Wool Dyeing, 1-51 (2013).

34. Lewin, M., Pearce, E.M. Handbook of Fiber Chemistry, Revised and Expanded, Crc press, (1998).

35. Uddin,M.T.Islam,M.A.Mahmud,S.,Rukanuzzaman,M. Adsorptive removal of methylene blue by tea waste, Journal of Hazardous Materials, 164, 5360 (2009).

36. Zheng, H., Liu,D., Zheng, Y., Liang,S., Liu, Z. Sorption isotherm and kinetic modeling of aniline on Cr-bentonite, Journal of Hazardous Materials, 167, 141-147 (2009).

37. Boparai,H.K. , Joseph, M. ,O’Carroll, D.M. Kinetics and thermodynamics of cadmium ion removal by adsorption onto nano zerovalent iron particles, Journal of Hazardous Materials, 186, 458-465 (2011).

38. Yen, C.-H., Lien, H.-L., Chung,J.-S.,Yeh,H.-D. Adsorption of precious metals in water by dendrimer modified magnetic nanoparticles, Journal of Hazardous Materials, 322, 215-222 (2017).

(Received 13/3/2017 Accepted 18/4/2017) 


\title{
استخام مخلفات ألياف الصوف المعلثة كمواد مازة منخفضة التكلفة لإزالة صبغة الميثيلين الزيرقاء \\ من الاوسناط المائية
}

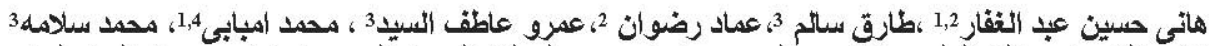

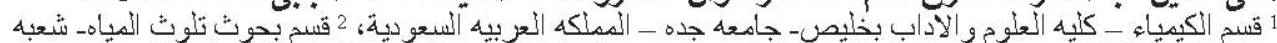

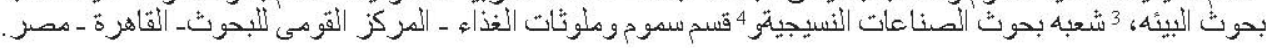

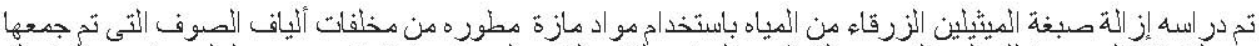

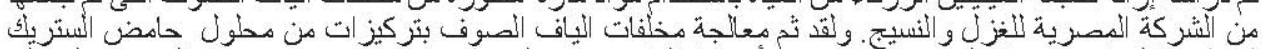

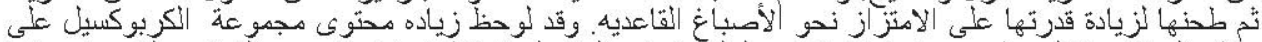

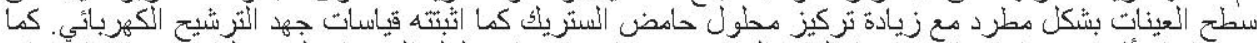

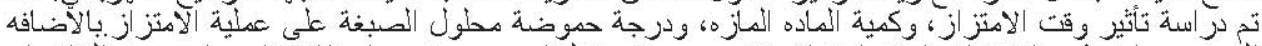

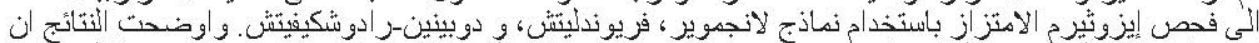

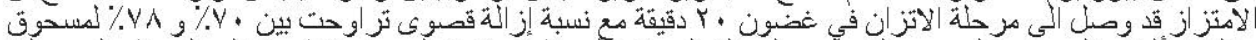

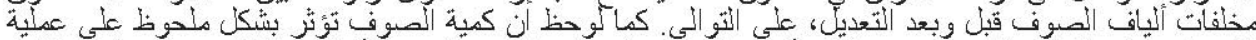

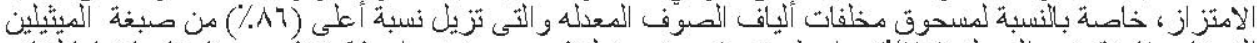

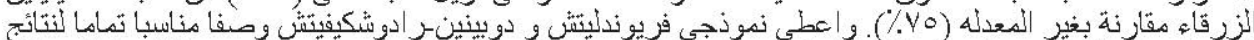

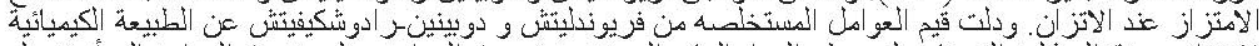

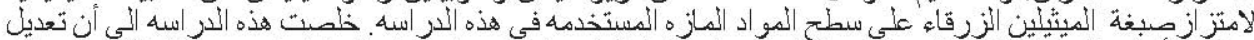

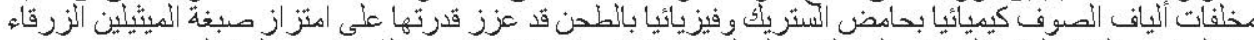

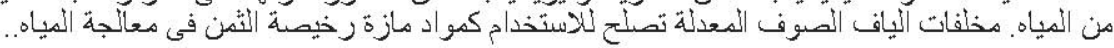

